\title{
The European Union and Global Governance
}

\author{
Remarks by Dr Fraser Cameron, Director of Studies at the European Policy Centre, \\ Brussels, Belgium, at the National University of Australia, 10 March 2004
}

\section{Introduction}

One of the central motives in establishing the Convention on the Future of Europe under former French president Valery Giscard d'Estaing, was to enable the European Union (EU) to play a stronger and more effective role on the world stage. But as the Convention entered the home straight in the spring of 2003, after more than a year of deliberations, the Iraq crisis exposed deep divisions in the Union's common foreign and security policy (CFSP), prompting some critics to ask whether the EU should continue with its global pretensions. The Iraq war also raised fundamental questions about the future of multilateralism which I will address later.

First, I would like to suggest that while the draft Constitutional Treaty produced by the Convention only provides a shaky basis for a more coherent EU foreign policy, the Iraq crisis, as with previous crises, is likely to galvanise the Union towards a more prominent and effective role on the world stage. The draft treaty (although currently in cold storage) contains a number of interesting proposals aimed at strengthening the Union's external representation. These include legal personality for the Union, the new post of EU foreign minister, an EU diplomatic service and a potential single voice for the Eurozone.

In addition, European leaders in December 2003 gave a warm welcome to the security strategy paper presented by Javier Solana, the EU's High Representative for CFSP. The central messages in this paper were the need for the EU to be more pro-active, to promote "effective multilateralism" and to strengthen international law. Partly because of its own history of sharing sovereignty and constant inter-governmental negotiations, the EU has been more willing than the US and many other countries to work through multilateral institutions.

In seeking to strengthen global governance, the EU is on an opposite track to the present governments of Australia and the United States (US). The Australian foreign minister has been rather dismissive of the United Nations, preferring "coalitions of the willing" in tackling international security issues. As for the US, it has a dismal record in recent years with regard to UN financing, the rejection of the Kyoto protocol, the efforts to destroy the International Criminal Court (ICC) and the refusal to ratify a host of UN and in particular arms control treaties such as the comprehensive test ban treaty (CTBT). In addition, its rhetoric such as "you are with us or against us" is hardly conducive to a multilateral approach. I believe that the approach of the current US and Australian administrations is both wrong and short-sighted. 


\section{The EU's foreign policy record}

Before discussing the EU's global aims it is worth examining briefly its record as a foreign policy actor. The common foreign and security policy (CFSP) proudly established at the 1992 Treaty of Maastricht, could hardly have started at a worse moment. As Yugoslavia began its freefall into a vortex of violence it proved anything but "the hour of Europe". Apart from the horrible conflict in the Balkans, the early years of CFSP were dogged by disputes on structures (community versus intergovernmental approach) and whether the Union should develop its own defence capabilities separate from NATO.

Some useful 'joint actions' were taken. For example, the first Stability Pact helped reduce ethnic tensions in the Baltic States by providing assistance for language training and minority rights legislation. The Union steadily increased its budget for technical and training assistance to third countries (expenditure on external policies is now euros 4.5 billion a year) and negotiated a network of agreements with its neighbours and countries further afield. Enlargement may be viewed as a major security policy, expanding the rules-based EU across the continent. Gradually the EU learned from its mistakes in the Balkans and today the Union can justly be proud of its achievements in stabilising the region and designing a road map for eventual EU membership. Later this year the EU will take over from NATO the SFOR mission in Bosnia.

On the institutional side, perhaps the biggest step forward in the past decade was taken at the 1997 Amsterdam IGC with the agreement to establish a High Representative for CFSP, a title that is hardly ever used. To the outside world Javier Solana is simply "the EU's foreign policy chief'. Not all EU foreign ministers appreciate this description, as under the treaty he is there "to assist the Presidency". But no one can dispute that Solana has put a face to EU diplomacy and given the CFSP a certain credibility. He is the EU representative in the Quartet dealing with the Middle East, he has put out brush fires in the Balkans and his telephone number is well known in Washington.

Although Colin Powell has Solana's telephone number, Washington may also need to call Chris Patten or one of several other Commissioners dealing with aspects of external relations. Washington may also wish to speak to one of the EU's special representatives dealing with the Middle East, the Great Lakes, or Kosovo. Depending on circumstances, the EU may be represented, therefore, by Solana or the presidency alone, the presidency and the Commission, or by all three. To say that many of the EU's partners find the situation confusing is an understatement.

Another new institutional development has been the establishment of the political and security committee (known as COPS rather than PSC). This Brussels-based body, made up of ambassadorial level representatives from member states, has developed quickly into an influential body providing strategic guidance, political oversight and continuity. A dramatic change to 1992 is the number of men and women in uniform now working for the Council. Some of them will now have an independent military planning role for operations where NATO does not wish to become involved. 
Progress has also been made on the defence front. Pushed by Britain and France, the EU is set to establish a 60,000 strong rapid reaction force mainly for peacekeeping purposes. The EU has already carried out successful police and military operations in Bosnia, Macedonia and the Congo and further engagements are on the horizon. Of course more needs to be done to improve EU defence capabilities and the new Armaments Agency should help in this regard.

Another area where the EU potential remains unfulfilled is diplomatic. The EU and its member states dispose by far the largest diplomatic network in the world. More than 40,000 officials work in the foreign ministries of the member states and the circa 1500 diplomatic missions abroad. Each member state maintains between 40 and 160 diplomatic missions while the Commission has a network of over 120 delegations around the world. These numbers will increase significantly as a result of enlargement. In comparison, the US has about one third of the human resources that the EU devotes to diplomacy and one fifth of the diplomatic missions. It is not apparent, however, that the US is less effective than the EU in pursuing its policy objectives.

Some critics argue that much more could have been achieved in CFSP with more qualified majority voting (QMV). I think this is doubtful. Foreign policy remains a sensitive area and member states are keen to retain some room for manoeuvre. Foreign ministries are also reluctant to negotiate themselves into oblivion. There also remain significant differences of foreign policy culture, experiences and expectations within the member states and these differences are likely to be accentuated as a result of enlargement. The very limited areas for using QMV in CFSP have hardly been used, mainly because there is a strong feeling that member states should not be pushed into a corner when vital national interests are at stake. CFSP is a process and the task of the institutions is to make it easier for the member states to integrate their efforts and then to promote common policies more effectively.

The proposals on the table at the IGC should lead to a further strengthening of CFSP. But as was brutally evident in the Iraq crisis, at the end of the day CFSP depends on the political will of its member states. There are inevitable limitations in the conduct of foreign policy in a Union which is reluctant to grant the institutions the authority that Pascal Lamy enjoys in trade policy. This means that in some important areas the EU will continue to find itself ham-strung but these areas are becoming fewer as the member states come to accept the advantages of working together.

\section{The EU's Representation in International Economic Fora \\ Trade}

The confused external representation of the EU in CFSP is mirrored in many other policy areas. The one notable exception is trade policy which has been an area of community competence for some time. In international trade negotiations it is the Commissioner for Trade (Pascal Lamy) who represents and speaks for the EU. The advantages of this approach for all member states have been proved in many trade negotiations, from the Kennedy Round to the launching of the Doha Development Agenda. The approach is simple. The EU Council of Ministers agrees a mandate which the Commission then uses 
as the basis for its negotiations with third parties. After agreement is reached, the Commission presents the results to the Council for approval. Such an approach could usefully be used in the foreign and international economic policy fields.

\section{Environment}

In the environment arena, an area of mixed competence between the community and the member states, there has been an ad hoc approach in recent years to maximize the EU's impact in international negotiations, to facilitate preparations and to ensure continuity. In the negotiations on climate change and implementation of the Kyoto Protocol, it is the Presidency which negotiates on behalf of the EU although the Commission plays an important role, in particular on issues which need to be coordinated and harmonized.

In the Commission on Sustainable Development (CSD) the EU adopted a "lead-country approach' and in the biosafety negotiations it turned to a "team approach".

\section{Economic/financial}

Despite the introduction of the euro, the EU continues to punch below its weight in international financial and economic fora. With the shift, in euro zone countries, of monetary policy sovereignty from national level to the European Central Bank (ECB), one would expect the EU's role in international economic and financial governance to have increased significantly. Unfortunately there are still problems stemming from the non-membership of some member states in the eurozone and jealousies both as regards the role of national finance ministries and participation in G7/8 meetings.

So far, ad hoc solutions to external representation have prevailed for the IMF, G7 finance ministers, the Financial Stability Forum, the G20 and other groupings where issues relevant to EMU are discussed. Member states have begun to realize, however, that these ad hoc solutions are not the best way for the EU's voice to be heard internationally. There is also increasing pressure from emerging markets and non-European G7 countries for streamlining EU representation in bodies such as the IMF.

In 1998, the European Council agreed rather complicated guidelines on the Union's external representation in financial fora. For meetings of $\mathrm{G} 7$ finance ministers 'the president of the ECOFIN Council, or if the president is from a non-euro area member state, the president of the Euro 11, assisted by the Commission' participates. Union views on other issues of particular relevance to the EMU would be presented at the IMF board by 'the member of the executive director's office of the member state holding the euro presidency, assisted by a representative of the Commission.' On issues of particular relevance to economic and monetary union, the European Council conclusions encouraged the Commission, Council and member states to prepare common positions for presentation in international fora but it was recognized that this might be hindered by not being fully associated with the preparatory processes of international meetings.

The above situation is clearly highly confusing. Ultimately it is to be hoped that there would be a single EU seat in the IFIs. But the question is how to get there? There are those who argue for a gradual approach, placing the emphasis on improved co-ordination sur place in Washington. Others suggest that as the IMF agenda is increasingly 
dominated by issues concerning EU competence, the EU should play a more prominent role through the EU Council dealing with economic and financial issues (Ecofin). This would mean Ecofin discussing IMF issues at their regular meetings and adopting common positions.

A further complicating issue is Britain's self-exclusion from the euro zone. This may be overcome if and when Britain joins the euro but until then only piecemeal reform is likely. The draft constitutional treaty does, however, provide for the possibility of the eurozone members agreeing on their own external representation. A step towards this goal might be a joint Franco-German seat, as these two countries have traditionally been pioneers in European integration.

\section{Abolish the G8?}

In recent years there has been mounting criticism of the G8 for its lengthy communiqués, lack of follow through, lack of transparency and restricted membership. Given the lack of substance of G7/8 meetings, it is not surprising that there have been calls, not just from anti-globalization protesters, to abolish the G7/8. Abolition is unlikely but the G7/8 could either be transformed into a G20 (upgrading the existing G20) or a G3 with the US, EU and Japan or East Asia as members. As in any international grouping there is often a trade off between increased size, and thus greater legitimacy, and reduced size, and allegedly greater efficiency. After the 2003 meeting in Evian there were a chorus of calls to abolish the G8. Despite this pressure it is unlikely that the current members will agree to change the status quo as it suits their vested interests.

\section{Gradual reform}

The external representation of the EU is thus a complicated process but there are clear challenges to more effective EU participation in international bodies. First, how to develop effective and coherent EU representation within bodies that were set up for a membership comprising only states. Some argue that an EU seat at the UN would not be possible under present international law.

Second, there are challenges for reaching common EU positions. This applies on the economic and financial front as well as the political front. For example, the EU has been largely invisible in international efforts to deal with the recurrent financial and banking crises caused by the sharp swings in capital flows to emerging markets. No coherent EU position has ever been developed and defended, even in cases where Europe's strategic interests are clear, e.g. Turkey. In contrast, the US usually has well defined positions and is highly effective at influencing multilateral bodies such as the IMF.

Third, there is the challenge of enlargement. If the enlarged EU of 25 member states can speak with one voice, then clearly it will increase its influence on the world stage. But the Iraq crisis revealed differences between old and new member states, especially in attitudes towards the US. It is likely, however, that the new member states will align themselves, as they have done in the past few years, with the mainstream of EU policies. They will recognize the value of the EU speaking with one voice. Already, apart from Romania, they have withstood US pressure to sign bilateral agreements on the ICC. 
Another challenge is how to encourage the US back in to the multilateral fold? Some argue that we shall have to await a change of administration. Others argue that the EU needs to seek allies and proceed regardless of Washington. I would suggest that the EU needs to remain engaged with whatever administration is in Washington (or Canberra), firmly maintaining its position as regards the importance of a rules-based international system.

In the end, a Union with 450 million citizens, the largest trading bloc in the world, with a single currency, the largest provider of development aid and humanitarian assistance, cannot escape from playing a greater role in world affairs. But it will be some time before it speaks with a single voice in all international fora.

\section{The EU and the UN}

One of the central plans of the Solana security strategy paper was the importance of strengthening global institutions and in particular the UN. Here is a significant area of policy difference with the US. Listening to the unilateralist rhetoric of the Bush administration, it is sometimes difficult to believe that the US played a decisive role in creating the United Nations. Without the leadership and inspiration of Franklin D. Roosevelt the UN would never have come into being. Roosevelt was acutely aware of the dangers of not engaging constructively with other nations and understood that a rulebased system of international co-operation was one of the conditions for global peace and prosperity.

It is all too easy to mock the UN's record and institutional structure. Largely due to Cold War paralysis it has not played a major role in resolving international conflicts. Its institutional structure strikes many as absurd. In the General Assembly, a patchwork quilt of 191 diverse nations - democracies and tyrannies, affluent and poverty-stricken, secular and fundamentalist - debate as equals. In this cosmopolitan talking shop, the US and Australia have the same voting power as East Timor and Vanuatu.

Yet for all its flaws, the UN remains indispensable. As a provider of humanitarian assistance, a keeper of the peace in the aftermath of military conflicts and a repository of expertise in the task of nation-building, it has proved its credentials - ask the people of Cambodia, Bosnia or East Timor. Even as a weapons inspector, the UN has proved its mettle. After all, the failure to find weapons of mass destruction in Iraq only illustrates the success of UN inspection programmes in the early 1990s.

But the UN is indispensable in a deeper way: As Hilary Charlesworth has argued, there is no credible alternative to rules-based international co-operation. The US doctrine of unilateral pre-emptive attacks on nations that it deems a threat is illogical and unsustainable. This is because the US cannot reasonably arrogate to itself rights that it would not willingly grant to other nations.

Mr Annan has set up a high-level panel to report on how to tackle threats to member states of the UN including "criteria for an early authorisation of coercive measures". The 
Solana strategy documents goes in the same directions. The EU must do all it can to strengthen existing international regimes - but it must also be prepared to act, preferably within the UN framework, if the rules are broken. Some European leaders, such as Tony Blair and Dominique de Villepin have gone further arguing that the international community also has a duty to protect citizens from authoritarian leaders' who systematically violate human rights. This challenge to the untrammeled sovereignty of the Westphalian system of nation states is likely to intensify as we become more of a global village.

Despite its enthusiasm for the UN, the UN also poses a special problem for the EU. Two of the member states, Britain and France, are permanent members of the UN Security Council and are supposed to inform and take into account the views of the Union as a whole. Although co-ordination between member states at the UN has improved in recent years (for the past five years the member states have voted together on $95 \%$ of issues), there is still some criticism of Britain and France pursuing national as opposed to EU interests in the UNSC. The EU is currently debating a number of proposals to strengthen the EU's role on the UN. Although both London and Paris are on record as favouring reform of the UNSC, the proposed changes (adding Germany and Japan) would only further accentuate the northern imbalance. How can the total exclusion of Latin America, Africa and the Middle East make sense?

The EU must now gather allies to find a way of restructuring the UN's main institutions to make them more effective and relevant for today's challenges. Terrorism, while significant, is far from the only challenge. The global community also needs to tackle the threats stemming from extreme poverty, gross inequality within and between nations, climate change and environmental degradation, and the uncontrolled spread of infectious diseases. These are all spheres in which effective transnational co-operation is vital and were recognized during Kofi Annan's visit to the European institutions in late January this year.

\section{Priorities in Global Governance}

The global institutions are a global public good. They are only as good and as efficient as the members wish. The alternative, however, is the law of the jungle. The aims in strengthening and reforming the multilateral institutions should be improving transparency, legitimacy and efficiency. The UN and WTO should be the first priorities; the UN because of Kofi Annan's urgent call for reform to ensure that the UN remains relevant in tackling the new security threats; the WTO because of the importance of trade issues for the developing world. WTO reform should not, however, be used as an excuse to postpone the Doha development round. Post Cancun, we need need to pay more attention to the problems of involving the low-income developing countries in global governance.

Another key area is democratic oversight. I believe consideration should be given to some form of parliamentary oversight of global institutions. There are already proposals on the table for a parliamentary assembly for the WTO. We also need to examine the 'best practices' for dealing with international civil society, and to 
agree criteria for their structured involvement in governance. We need to promote the expansion of global public policy networks and global public goods.

Two further points for the EU. The EU should do more to assist and support regional cooperation and integration in other parts of the world. And the Eu should take steps to end the present de facto EU/US duopoly in the IMF and World Bank.

\section{The Importance of Multilateralism}

There is little doubt that 9/11, the war on terror and the invasion of Iraq have had a major impact on normative values in international relations. To many, the international system is generally perceived as an anarchy with little if any consciousness of society and with no authoritative institutions that are in a position effectively to promote or to enforce norms. In many respects, this is a correct image. There is no world government, no overarching authority embodying and regulating international society. States are sovereign. They do what they want, except to the degree that they are constrained by the countervailing power of other states.

Yet this is a partial vision. Norms may be weaker in the international system. The consciousness of being bound together in social relations is less developed than it is within states. But there are important shared understandings of right and wrong and of appropriate and inappropriate behaviour. This is reflected in the care with which states seek to justify their actions by reference to normative principles. There is considerable value in viewing international relations in social terms, and, more specifically, in enquiring as to the extent to which states accept rule-based constraints on their behaviour.

Since 1945 there has been a gradual, but accelerating, development of the normative framework of international relations. This process of mutlilateralising world politics has been geographically uneven, perhaps strongest in Europe and weaker elsewhere. But the trend has been unmistakable. And it has been a trend that embraced and constrained the great powers as well as the small. This has contributed to more civilized and humane state conduct. War is rarely chosen as an instrument of policy and most states show an increasing attentiveness to what are arguably universal norms of human rights. Their affairs are increasingly bound up in, and constrained by, co-operative multilateral institutions and by bodies of what they recognize to be law.

This trend inevitably has had an impact on the principle of untrammeled sovereignty, a principle which originated even before the 1648 peace of Westphalia. The Charter of the United Nations universalised the principle of sovereignty in Article 2 and simultaneously embraced the principle of non-intervention in the internal affairs of a state.

Admittedly, these principles were often breached during the Cold War but they did lay a normative basis for international relations in the early 1990s. Unilateral intervention for self-interested purposes decreased sharply. Where major interventions occurred, as, for example, in Bosnia or in Somalia, they tended to be multilateral rather than unilateral and 
they were justified on the basis of widely accepted normative principles rather than power politics.

The principle of nonintervention is embedded in a wider consideration of the legitimate and illegitimate use of force in international relations. The Charter explicitly prohibited the use of force in relations between states, with two exceptions. The first was what it referred to as the inherent right of self-defence in the event of armed attack. And the second was under Chapter VII in circumstances where the Security Council determined the existence of a threat to peace and security and where peaceful means of resolving the issue in question had failed.

At the same time there has been a change in attitude towards the broad issues of human rights and democracy. In the traditional international system, neither of these issues was considered to be a matter of legitimate international concern. We have witnessed, however, in the past 15 years a clear expansion in the rights and responsibilities claimed by international institutions in both spheres. These include not only the hard end (e.g. the Convention on Genocide and the debate regarding humanitarian intervention), but also more everyday questions, such as the rights of children, indigenous peoples, women, the disabled, not to mention the prohibition on racial discrimination and torture. All of these have come to be seen as matters of legitimate international concern.

Many states consequently now accept that sovereignty is qualified by the responsibility of the state to protect its citizens from harm. International institutions have also become increasingly active in the promotion of democracy within states, and in the protection and restoration of democracy when it is under threat.

Each of these trends is affected in important ways by the evolving war on terror. It is not that just any state is questioning them; the world's only remaining superpower is. And, in the absence of authoritative institutions, the durability of norms in international politics depends in considerable measure on the support of the powerful. It doesn't really matter whether Vanuatu challenges the rules. It does matter when the US challenges.

Various arguments were put forward by President Bush (and Tony Blair) arguing the case for war against Iraq. These included the inherent right of self-defense as Iraq was allegedly preparing to use WMD (at one stage Washington also attempted to argue that Iraq was harbouring terrorists and therefore that the US was authorized under UN resolutions to act against it); and the right to use force in the face of an imminent threat but as George Tenet has reminded us there was no such imminent threat.

President Bush then fell back on an argument concerning preventive defence. This boils down to the proposition that if another state might at some stage develop, deploy or transfer capabilities that might be threatening to the United States, attacking it would be an act of self-defence. The bottom line here: if such an argument stands, the normative constraint on the use of force is profoundly weakened throughout the international system. Anybody could be a potential threat to anybody. Furthermore if the US abrogates 
to itself the right to remove any hostile or even noxious regime, it is hard to see what is left of the principle of non-intervention.

Turning to the human rights dimension, I think it is fair to say that the war on terror has had significant implications for internationally recognized human rights. The extreme case is, of course, Guatanamo Bay, but there is growing evidence of pressure on norms regarding the use of torture and concerning the transfer of persons across international frontiers to places where there is a reasonable presumption that they may be tortured. Moreover, it appears that the monitoring dimension of the war on terror has significant implications for privacy rights. And finally, the war on terror has placed substantial further pressure on an already beleaguered refugee and asylum system.

It is, of course, too early to judge the impact of the war on terror and the associated war on Iraq on the normative framework of international relations. Moreover, we don't know whether this direction in American policy will endure. President Bush stands a good chance of losing the 2004 election. It is unclear whether any successor would display quite the same proclivities or would enjoy the same carte blanche on security issues. The effort to pacify and hold Iraq may be sufficient to dissuade the United States from similar efforts elsewhere.

Whatever the case, it is reasonably clear that the war on terror does have significant potential to weaken norms underpinning both order and justice in international relations. The obvious danger in these areas stems not just from the acts of the superpower, but also from the possibility of emulation. If the strongest power in the system ignores norms concerning nonintervention and the non-use of force, others may also feel less constrained in doing so.

\section{Conclusion}

We stand at a cross roads in international relations. A crucial factor will be the future course of American policy. The world's only hyperpower has unrivalled military capabilities but it is doubtful that alone (or even with the assistance of the UK and Australia) it can achieve a durable Pax Americana. Given the size and soft power of the EU, it has an important role to play holding up the torch of multilateralism. But for the torch to stay alight the EU will have to take on more regional and global security responsibilities and demonstrate to the sceptics in Washington that multilateralism can lead to effective solutions to security threats and other global issues.

In the 1990s there was a growing trend, promoted by the EU and likeminded countries, towards serious consideration and promotion of international justice. The trend is admittedly weak, but it was there in the increasingly wide engagement of international institutions in matters of domestic jurisdiction related to legal, political, and social rights. Regrettably, the war on terror has expanded the opportunities for states to violate those rights with impunity.

Finally, the willingness of states to resolve disputes through cooperative effort rests in considerable measure on the willingness of the strongest to do so. To the extent that the 
weaker see the stronger to be constrained by cooperative structures, their incentive to commit to these structures is greater. If on the other hand, cooperative approaches are spurned by the great powers, or are approached on the basis of diktat rather than real consultation and consensus, then the multilateral mechanism is itself discredited.

The EU's fight to strengthen the institutions of global governance is thus a fight that we should all support. 